\title{
EPOVB

\section{EPOVB Award Winners 2021}

(c) Springer Science+Business Media, LLC, part of Springer Nature 2020

APSA's Elections, Public Opinion, and Voting Behavior (EPOVB) Section welcomes nominations for the following section awards. The deadline for submitting nominations is March 1, 2021. Please submit nominations directly to the designated committee chair. Self-nominations are welcome. Awards will be made at the APSA 2021 meeting.

- Best Paper Award (recognizing an EPOVB paper delivered at APSA 2020). Chair, Yanna Krupnikov (Stonybrook), yanna.krupnikov@ stonybrook.edu.

- Emerging Scholar Award (recognizing a top scholar in the field who is within 10 years of the PhD). Chair, Eva Anduiza (Barcelona), eva.anduiza@uab.cat.

- John Sullivan Award (recognizing a paper delivered by a graduate student on an APSA 2020 EPOVB panel). Chair, Michael Tesler (UC, Irvine), mtesler@ uci.edu.

- Best Article in Political Behavior Award published in 2020. Chair, Barry Burden (Wisconsin, Madison), bcburden@wisc.edu.

- Philip E. Converse Award (for an outstanding book in the field published at least 5 years before). For full consideration for the Converse Award, please send a copy of the book to each member of the Converse Award Committee: Chair, Christopher Karpowitz (Brigham Young University), ckarpowitz@byu.edu. Tim Ryan (University of North Carolina, Chapel Hill), tjr@email.unc.edu; Susan Banducci (Exeter), s.a.banducci@exeter.ac.uk.

More information, including full committee rosters, is at https://www.apsan et.org/section32.

Publisher's Note Springer Nature remains neutral with regard to jurisdictional claims in published maps and institutional affiliations. 